\title{
La democracia en un grupo de élite política leonesa
}

\author{
Democracy within an elite political group in the society of Leon
}

Carlos Alejandro Montes de Oca Estrada ${ }^{1}$

\begin{abstract}
SINOPSIS: El presente artículo da cuenta de los resultados de una investigación de tipo cualitativa y exploratoria sobre las representaciones sociales de la democracia al interior de un grupo de élite política en el municipio de León, Guanajuato, compuesto por 15 sujetos. Su objetivo general fue explorar dichas representaciones y los particulares identificar sus procesos de producción. Se aplicó la etnometodología como metodología, como técnica la entrevista no estructurada y su análisis fue a partir de la aplicación de 9 indicadores previamente diseñados. Entre sus aportes están: una mayor comprensión de la sociedad leonesa, del núcleo figurativo de las RSD y se identificaron los modos y procesos de constitución del pensamiento político-social de la democracia; como también se comprendió el "sentido común" que utiliza la élite para actuar y/u orientarse ante su "democracia".
\end{abstract}

Palabras clave: representaciones sociales, democracia, élite política.

ABSTRACT: This article reports the results of a qualitative research and exploratory type of social representations of democracy within a group of political elite in the city of Leon, Guanajuato, composed of 15 subjects. Its overall objective was to explore these representations and individuals identify their production processes. It was applied the ethnomethodology as the unstructured interview methodology and analysis was from the application of 9 indicators applied previously designed as a technique. Among his contributions they are: a greater understanding of the society of Leon, the figurative core of RSD and modes and processes of formation of political and social thought of democracy were identified; as the "common sense" used by the elite to act and / or oriented to their "democracy" is also included.

Keywords: social representations; democracy; political elite.

\section{Introducción}

Hoy en día la democracia es un tema tan socorrido como debatido, tan cuestionado como reivindicado; tan amplio y ambiguo como concreto y determinado; así como popular y elitista. Es tan mencionado en el discurso académico que se logró integrar una lista de más de trescientas definiciones hechas por filósofos, moralistas, jefes de estado y periodistas, y la mayoría la asumió como propia, que estaban de acuerdo con ella. Así mismo, ha sido estudiada por las ciencias sociales en general y particularmente por la psicología social, y sobre todo a partir del colapso del bloque soviético (Marková, 2004).

Así, los hay quienes sustentan o reivindican la democracia ya sea para legitimarse, así como para denostar quienes practican lo contrario a sus valores. También ha resultado la principal creencia del mundo contemporáneo (Marková, 2003; Alonso, 2002).

\footnotetext{
${ }^{1}$ Doctor en ciencias sociales por la Universidad de Guanajuato, Campus León. Docente en varias universidades - División de Ciencias Sociales, Universidad de Guanajuato, Campus León - León, Guanajuato, México. Correo electrónico: camontesdeoca@yahoo.com.mx.
} 
El discurso de la democracia en el mundo occidental, como todo fenómeno social, ha tenido un proceso en construcción, un continuum, mediante el cual se podría explicar tanto su proceso y como su mecanismo (Iñiguez \& Vázquez, 2006). Es decir, no ha sido siempre el mismo desde que surgió con los antiguos griegos, ni ha tenido una sola acepción entre quienes la reivindican, además de que, por ende, se ha manifestado de múltiples formas a lo largo de la historia y en las distintas latitudes.

Históricamente, la democracia no emergió desde el statu quo o de quien detenta el poder, sino que ha sido una necesidad demandada desde la oposición política al régimen en el poder. En otras palabras, ha sido la democracia un régimen político pugnado, reivindicado e impulsado por las núcleos sociales desfavorecidos, tanto en lo económico como en lo social, así como organizaciones políticas opuestas al régimen político en turno (Meyer, 2007).

En la perspectiva de definir el concepto de democracia uno se enfrenta a varias dificultades: primero, tiene un carácter polisémico, es decir que su significado varía dependiendo de la orientación disciplinaria desde la cual se aborda; en segundo, es un concepto que está íntimamente relacionado con otros como la política, la ciudadanía, la cultura política y el espacio público/privado, entre otros; tercero, es un campo que se disputan todas las referencias geopolíticas, esto es, las izquierdas, derechas y centro, así como liberales, conservadores o socialistas que dicen luchar por sus valores; reside en los distintos puntos de vista disciplinarios desde la cual es estudiada, así como la gran variedad de fenómenos que, en cuanto su descripción y explicación, convergen disciplinas tan diversas como la antropología, la sociología, la ciencia política, la psicología social y el psicoanálisis (Iñiguez \& Vázquez, 2006; Svampa, 2007).

El actual régimen político mexicano que se declara "democrático" ha sufrido múltiples transformaciones desde que en 1917 se incorpora a la Constitución nacional su acepción democrática, como resultado de la correlación de fuerzas políticas triunfantes de la revolución de 1910. Ha transitado de un régimen históricamente autoritario a uno declaradamente democrático con instituciones que pretenden responder al ejercicio democrático (Navarrete, 2008).

Así, esa democracia se encuentra en la más profunda de las crisis debido al ambiente de incertidumbre generado tanto por la crisis económica como por el temor a la violencia del crimen organizado. El desarrollo institucional que se había venido dando desde la controvertida elección presidencial de 2006 se ha visto impactado por factores ajenos al compromiso democrático de la ciudadanía y la sociedad civil (Parras, 2010).

En ese sentido, hay voces que afirman que no ha habido democracia en el país. Así lo señala Ackerman (2014):

México no cumple con los estándares mínimos para ser considerado como un régimen democrático. Por lo tanto, las luchas ciudadanas tendrían que orientarse hacia la transformación integral del sistema de dominación y control que mantiene a más de 60 millones de mexicanos en la miseria y a todos en un total estado de indefensión. No es suficiente cambiar de nombres a las mismas instituciones de siempre o modificar artículos legales que jamás se aplicarán. Tal y como lo señaló hace más de cincuenta años el gran maestro Pablo 
González Casanova en su obra clásica, La Democracia en México, México solamente avanzará si logramos transformar la estructura del poder social y política que subyace y controla desde fuera al sistema institucional formalmente constituido (Ackerman, 2014) .

La democracia, como todo objeto social, es susceptible de constituirse en una representación social, formándose así las representaciones sociales de la democracia (RSD) cuyo estudio ha sido modesto, comparativamente hablando con los demás temas estudiados de las RS.

Las representaciones sociales (RS) nos explica el "sentido común" de la gente, como producto de una interacción social e individual, es decir en una dimensión inter e intrasubjetiva. Uno de sus propósitos es hacer algo familiar que antaño era desconocido, con la posibilidad de clasificar y nombrar a los nuevos acontecimientos e ideas, asimilando esos fenómenos a partir de una gama de ideas, valores y "teorías" que ya existían y son aceptados en el entorno social (Jodelet, 1986). Así, nos permiten construir discursos sobre la realidad que experimentamos: qué y cómo entendemos determinados fenómenos sociales; son una forma de conocimiento del mundo que a su vez, tienen que ver con los estereotipos, los prejuicios y las actitudes. Nos explican la manera como conocemos, percibimos, valoramos, justificamos y nos guían por el mundo (Rodríguez, 2003).

Las RS no tienen ruptura entre el interior y exterior, entre el objeto y sujeto de la persona, lo que significa que el sujeto - individual o colectivo - y lejos de asumir pasivamente el papel interactivo, interactúa activamente en la construcción de su representación, de tal manera que su praxis social lo orienta a integrar los procesos propios de las RS que le son significativas. (González, 2003). Tiene por objetivo traducir un género de conocimiento científico al sentido común, teniendo como función la elaboración de conductas y una comunicación propia, gracias a las cuales se pueden hacer comprensibles la realidad física y social (Moscovici, 1979, 2007). Permite introducir el lenguaje y la cognición como dimensiones básicas de la cultura y la vida cotidiana. Constituye un espacio de investigación, donde el campo de la comunicación y el de la vida cotidiana se entrelazan. Como también facilita el análisis de lo que "ve", "interpreta" y "da sentido" a un grupo particular sobre sus vivencias individuales y grupales (Rodríguez, 2007). Son formas de conocimiento elaboradas y compartidas al interior de un grupo que participa de prácticas sociales comunes y que tiene una determinada inserción en su estructura social, una manera de interpretar y aprehender la realidad cotidiana; son un conjunto de fenómenos cognitivos que las personas poseen sobre diversos aspectos de la realidad (Ibáñez, 1994).

La aportación principal de las RS consiste en la conversión de una forma de conocimiento científico a un sistema compuesto de opiniones e interpretaciones de la realidad; así como dinamiza la constitución de conocimientos y pensamientos sociales en la comunicación y grupos de acción situados histórica y culturalmente.

Son tres los elementos que hacen emerger una RS, a saber (Moscovici (1979):

a) La dispersión de la información que son los datos de los que la mayoría de la gente dispone sobre un objeto social que puede ser muy cuantiosa o tremendamente escasa.

b) La focalización: es aquella atención que pone una persona o grupo en alguna zona en particular del medio y se aleja de otra. 
c) Presión a la inferencia: se refiere al momento en que aquella persona o grupo se ve obligado a tomar una decisión sobre las distintas opciones que se le presentan.

Moscovici (1979) distingue tres tipos de RS:

a) Hegemónicas: son aquellas RS que les es típico un alto grado de consenso entre los miembros del grupo altamente estructurado - un partido, una nación - sin que hayan sido generadas o producidas por el grupo y equivaldrían a las representaciones colectivas propuestas por Durkheim.

b) Emancipadas: aquella que emergen entre subgrupos específicos, portadores de nuevas formas de pensamiento social, del conocimiento o ideas pertenecientes al subgrupo y tienen cierto grado de autonomía.

c) Polémicas o controversiales: aquellas surgidas entre grupos que atraviesan por situaciones de conflicto o controversia social respecto a hechos $u$ objetos sociales relevantes $y$ ante los cuales expresan formas de pensamiento divergentes, la sociedad como un todo no las comparte y tienen un interlocutor imaginario.

Las RS se forman a partir de cuatro procesos en los que se puede observar: cómo lo social transforma un conocimiento en una representación social y cómo ésta, a su vez, transforma lo social, mostrando así la interdependencia e interacción entre la actividad psicológica y sus condiciones sociales de ejercicio (Araya, 2002; Pererá, 2005). Dichos procesos son:

a) Un fondo cultural acumulado en la sociedad a lo largo de su historia: constituido por las creencias ampliamente compartidas, los valores considerados como básicos y las referencias históricas y culturales que conforman la memoria colectiva y la identidad de la propia sociedad, materializándose en las diversas instituciones sociales, por ejemplo en la lengua y en general en todos los objetos materiales.

b) Los mecanismos de anclaje y objetivación. El primero de ellos concierne a la forma en que los saberes y las ideas acerca de determinados objetos entran a formar parte de las RS de dichos objetos y se sujetan al entorno social. Implica la integración cognitiva del objeto representado dentro del sistema de pensamiento preexistente.

c) El núcleo central: constituido por un código central y un entramado de elementos periféricos, que define el significado de la RS como un todo. El significado depende tanto de los factores contingentes de la naturaleza, del contexto inmediato, de la finalidad de la situación, como de los factores más generales que van más allá de la situación en sí misma (Abric, 2004).

d) El conjunto de prácticas sociales: son aquellas actividades diversas de comunicación social donde se origina principalmente la construcción de las RS. Tanto los mass media como la comunicación interpersonal son el detonante de la construcción de una RS.

\section{Problema}

Nuestro problema se ubica en el momento actual, en el municipio de León y su contexto histórico social. El sujeto de investigación está compuesto por 15 personas que forman y/o han formado parte de algún grupo élite política local, en los últimos treinta años cuando menos, que 
respondieron a la convocatoria. Está delimitado espacialmente en el municipio de León, estado de Guanajuato. Se llevó a cabo el trabajo de campo en el año 2013. El instrumento para obtener nuestra materia prima fue a través de la entrevista semiestructurada y su análisis se llevó a cabo por medio de 9 indicadores previamente diseñados.

En su ejercicio del poder, la élite política emerge de la necesidad de que la dirección política, administrativa, militar, religiosa, económica y moral sea ejercida por una minoría organizada para incidir en el ejercicio de su poder expresando su discurso de la siguiente manera:

Estos grupos de élite piensan, hablan y actúan en, desde y para la democracia, constituyendo la RSD, en una especie de "sentido común", base inter e intrasubjetiva que les permite ubicarse en un mapa determinado, como guía para saber dónde están, qué, cómo piensan y cómo actúan. De tal forma que nos permitiría identificar cuáles son nuestras fronteras de seguridad y orientación, a través del "sentido común" que nos hace pensar desde una perspectiva tan diferente como común y tan extraña como familiar.

En cuanto a la conformación de los sujetos de dichas RSD, hay en la sociedad mexicana determinados grupos que se caracterizan por su incidencia significativa en las decisiones más importantes de su comunidad, que son aquellos que conforman y pertenecen a la élite política. Ellos experimentan una socialización propia de su clase, en la que interactúan en un ambiente conformado por una información, una percepción selectiva y determinada de sus propios intereses; orientan su acción, dirigen sus comportamientos, condicionan sus adhesiones, delimitan sus grados de libertad a la hora de actuar y tomar decisiones; de esta manera se van familiarizando con lo extraño y lo novedoso, incorporándolos a sus esquemas cognitivos preexistentes; aplican un saber práctico al racionalizar sus prácticas sociales; se anticipan a otros grupos presentes en el campo social, condicionan fuertemente su sentido de actuación y adhesión al interior de sus grupos, justificándolos; refieren sus actuaciones a sus marcos cognitivos; crean a sus agentes y discursos, así como sus conceptos y definiciones; se ven afectados por su ambiente personal e impersonal; son responsables de acuerdos con ciertas normas con un "sentido común" inferencial. Así van desarrollando comportamientos, prácticas sociales y una identidad social; intentan y resuelven problemas conocidos o pueden prever cómo se resuelven utilizando las tradiciones socializadas y experiencias sancionadas por la práctica cotidiana en interacción con las personas y la cultura.

Para satisfacer sus necesidades, van imaginando y desarrollando tiempos y espacios propios que los van llevando a relacionarse con sus pares, creando organizaciones y estructuras en las que proyectan sus propias ideas, creencias y convicciones; sus emociones y sentimientos; sus virtudes y perversiones, sus altruismos y egoísmos; constituyendo los instrumentos necesarios para la comprensión de su dinámica social, una determinada visión del mundo que la gente aporta o lleva consigo y utilizan para actuar y/o tomar posiciones al respecto; para entender la dinámica de las interacciones sociales y, por lo tanto, para aclarar los determinantes de sus prácticas sociales, informando y explicando la naturaleza de sus nexos sociales, tanto al interior de un grupo al que pertenecen y en el que interactúan como con y entre otros grupos afines y/o diferentes; se introduce un determinado lenguaje y cognición propios de su vida cotidiana, de una cultura en este caso democrática. 
Estos grupos de élite piensan, hablan y actúan en, desde y para la democracia, constituyéndose en una RSD, en una especie de "sentido común", base inter e intrasubjetiva que les permite ubicarse en un mapa determinado, como guía para saber dónde están, qué, cómo piensan y cómo actúan. Para satisfacer sus necesidades, van imaginando y desarrollando tiempos y espacios propios que los van llevando a relacionarse con sus pares, creando organizaciones y estructuras en las que proyectan sus propias ideas, creencias y convicciones; sus emociones y sentimientos; sus virtudes y perversiones, sus altruismos y egoísmos; constituyendo los instrumentos necesarios para la comprensión de su dinámica social, una determinada visión del mundo que la gente aporta o lleva consigo y utilizan para actuar y/o tomar posiciones al respecto; para entender la dinámica de las interacciones sociales y, por lo tanto, para aclarar los determinantes de sus prácticas sociales, informando y explicando la naturaleza de sus nexos sociales, tanto al interior de un grupo al que pertenecen y en el que interactúan como con y entre otros grupos afines y/o diferentes; se introduce un determinado lenguaje y cognición propios de su vida cotidiana, de una cultura en este caso democrática.

Uno de los problemas a los que nos enfrentamos al inicio del trabajo fue la necesidad trazar un mapa con preguntas que puedan orientar la pesquisa de la investigación en un campo un tanto desconocido, como las siguientes:

¿Cuál es la élite política local? ¿Cómo identificarlas, abordarlas y entrevistarlas? ¿Cuáles son los partidos y las fracciones políticas con las cuales, a través de las cuales se organiza y establece bases sociales que le permite configurar redes de poder local y ser eficaz en la toma de decisiones públicas? ¿Cómo logra influir en las decisiones significativas que tienen que ver con la configuración espacial del municipio y que le posibilita mantenerse como élite política? ¿Cómo se establece la relación entre élite política y el resto de la sociedad como un cuadro de dominación política?

Estos grupos de élite política se encuentra en aquellos segmentos que tienen una incidencia significativa en las decisiones importantes de la sociedad y los podemos encontrar en ciertos sectores empresariales, en partidos políticos, en la alta jerarquía católica y grupos de profesionistas. En el caso de los empresarios, existen organismos que organizan a una buena parte de ese sector. Así, por ejemplo, está el Consejo Coordinador Empresarial (CCE) que en su objetivo y su estrategia trabaja para impulsar la democracia plena. Otro, la Confederación Patronal de la República Mexicana (COPARMEX) en sus “objetivos estratégicos" está el pugnar por un Estado democrático de derecho. La iglesia católica que tiene una gran influencia en la sociedad, su alta jerarquía está organizada en la Conferencia del Episcopado Mexicano (CEM) fija su posición en el marco democrático. En el caso local, existe un grupo organizado también influyente que es el Consejo Coordinador de Colegio de Profesionistas de León que plantea una demanda democrática al gobierno, la de integrar consejos ciudadanos.

Después de todas estas consideraciones en las que se observa cómo se construye el problema de las RSD, se plantean las siguientes preguntas por investigar:

- ¿Qué son las representaciones sociales de la democracia en la élite política leonesa?

- ¿Qué es y en qué consiste la estructura de dichas representaciones?

- ¿Cómo se construyen? 
El objetivo general fue explorar sus RSD y los específicos fueron describir los cuatro procesos de producción de las RSD a través de: el fondo cultural acumulado; los mecanismos de anclaje y objetivación, en sus cuatro fases: la selección, la descontextualización, la formación del núcleo figurativo y la naturalización; el núcleo central; las prácticas sociales.

\section{Método}

El presente reporte de investigación es de índole cualitativa en la que se aplicó como estrategia metodológica la etnometodología y como instrumento técnico la entrevista no estructurada; para su análisis se diseñaron nueve indicadores. La etnometodología nos permite conocer a un grupo social sui géneris, en el que se puede interpretar cómo las personas dan sentido a la vida cotidiana a través de su discurso y acciones, y permite interpretación de los hallazgos (Martínez, 2006).

El instrumento para obtener nuestra materia prima fue la entrevista semiestructurada y el diseño de sus preguntas fue en base a los componentes estructurales de la teoría de las RS, a partir de sus tres procesos en los que se puede observar cómo la condición social transforma un conocimiento en una RS y ésta, a su vez, forma parte de la subjetividad, mostrando así la interdependencia e interacción entre la actividad psicológica y sus condiciones sociales.

Dada la naturaleza metodológica se optó definir la población conforme la calidad y cantidad de información que se obtuviera. Así, me aboqué La selección de los informantes fue en un principio aquellos que estaban a la vista de la opinión pública y estos a su vez me fueron llevando a otros homólogos de tal manera que una vez que se iba obteniendo la información necesaria, se fue definiendo el número de participantes hasta lograr la materia prima lo más rica y menos repetitiva posible.

Inevitablemente surgen preguntas o dilemas como por ejemplo: ¿qué tan profundo y qué tan extenso debe ser el proceso de recolección de datos? ¿Por dónde iniciar y terminar el proceso de recolección de datos? ¿A quién incluir, a quién excluir de la recolección de datos? Frente a estas interrogantes, tenemos las siguientes respuestas.

Frente a la profundidad y la extensión, es prioritaria la profundidad y la explicitación de la calidad sobre la cantidad. El límite de la profundización se logra en la medida que avanza en el proceso de investigación, la extensión, en base las fuentes que han sido exploradas.

En cuanto a nuestros sujetos de investigación, se les explicó su motivo de estudio, solicitándoles su participación en atender una entrevista, de manera voluntaria y guardando su anonimato, grabándoles sus declaraciones; posteriormente se transcribieron. Se elaboró una guía de entrevista cuyas preguntas se diseñaron a partir de los cuatro procesos de la conformación de las RS: un fondo cultural acumulado; los mecanismos de anclaje y objetivación; un núcleo central y el cuarto es el conjunto de prácticas sociales.

Me di a la tarea de localizarlos, hacer la cita y entrevistarlos, así como suspendí la búsqueda de más informantes al momento que ya no me dieron ninguna comprensión auténticamente nueva, sino se repetía el discurso. Entre las personas que solicité entrevistarlas hubo otras 8 personas que después de insistir reiteradamente, se rehusaron a ser entrevistados. 
Con el objetivo de codificar y clasificar la información se diseñaron nueve indicadores que identifiquen los procesos y productos de las RSD observados en las entrevistas. Los elementos metodológicos a considerar que podrían generar la construcción de los temas ejes son: cómo se construyen, cuáles son los tipos, los componentes o dimensiones y las funciones de las RS, de lo cual podemos plantear los siguientes temas de las RSD.

\section{Indicadores}

Como ya mencionamos, se diseñaron 9 indicadores que permitieran el análisis del discurso que a continuación se presentan:

1) La pertenencia al grupo de élite política en León: aquella relación que mantiene o han mantenido con la estructura de alta jerarquía del poder político.

2) La asunción de puestos públicos o liderazgos plenamente reconocidos: aquella responsabilidad asumida en la conducción de algún grupo influyente en la estructura del poder político leonés.

3) La participación en la toma de decisiones en algún grupo de élite política en León: aquella intervención significativa asumida en alguna agrupación de élite política.

4) El reconocimiento de alguna virtud o valor democrático: admitir la certeza de algún principio democrático que norma u orienta responsablemente la conducta de quien lo asume.

5) El conocimiento de algún personaje y/o referencia histórica democrática: admitir aquella cognición de algún prócer o hecho histórico que ha contribuido a la construcción de la democracia.

6) El conocimiento de algún marco político democrático como guía de su actuar: aquella idea, "teoría" o creencia democrática que haya orientado su actuación.

7) La presencia de la congruencia democrática: aquella consecuencia ética entre el pensar y actuar democrático.

8) La presencia de algún aprendizaje democrático, ya sea por alguna persona o experiencia: aquella asimilación de alguna lección democrática.

9) La presencia de alguna experiencia significativa de alguna lectura, película o evento relacionado con el tema de la democracia.

\section{Resultados}

El estudio aportó una mayor comprensión de la sociedad leonesa al dar cuenta de cómo dicho grupo se apropió de su realidad integrándola a su actuación y anclándola en su cultura. Se desentrañó y cuestionó el núcleo figurativo de las RSD donde se articularon las ideas y creencias políticas de la democracia. Asimismo, se pudo identificar los modos y procesos de constitución del pensamiento político-social de la democracia que estamos viviendo actualmente. Además se pudo comprender mejor su "sentido común" que utiliza para actuar y/u orientarse ante lo que sus miembros considera como "democracia". 
En cuanto al primer proceso, a lo largo de su historia, la sociedad leonesa ha ido constituyendo un fondo cultural democrático conformado por las creencias ampliamente compartidas, los valores considerados como básicos y las referencias históricas y culturales que conforman la memoria colectiva y la identidad de la propia de dicha sociedad. Todo ello se ha materializando en las diversas instituciones sociales, empezando por el lenguaje que ha asignando el nombre a todo aquello que tiene que ver con la democracia y continuando con una serie de instituciones propias del ámbito democrático como son - ente otras - el ejercicio del poder a través de organizaciones sociales como son las aquellas instituciones del Estado que organizan y sancionan los comicios electorales, así como las agrupaciones empresariales, las ONGs y los partidos políticos. Así, se han conformado las RSD en la vida material en el conjunto de condiciones económicas, sociales, políticas e históricas.

El segundo proceso se pudo observar en sus dos mecanismos: el de anclaje y el de objetivación que provienen de la propia dinámica de las RSD. El primero, correspondió a la forma en que el fondo cultural democrático leonés acumulado se ha adherido en los miembros de la élite política mediante transformaciones específicas. El segundo, la objetivación, ha dado cuenta de cómo incidieron las estructuras sociales sobre la formación de las RSD y han intervenido en los esquemas ya constituidos en la elaboración de nuevas RSD.

El tercer proceso, el núcleo central, lo podemos observar a través del código central - la democracia - y su correspondiente entramado de elementos periféricos. Su significado se expresó tanto en los factores contingentes propios de los sujetos de estudio, su contexto inmediato, así como de los factores más generales: el contexto social e ideológico, el lugar en la organización social, la historia, los intereses sociales, así como los sistemas de valores de dichos sujetos de estudio.

El cuarto y último proceso es el conjunto de prácticas sociales democráticas en las que la a través de la comunicación social originaron la construcción de las RSD, como fueron la comunicación interpersonal y social que experimentaron los informantes transmisión, a su vez, el fondo cultural acumulado. Por ejemplo, los acuerdos logrados entre los miembros de la elite política, comunicándose interpersonalmente y/o informándose por otros medios masivos de comunicación acerca de la democracia leonesa.

En cuanto al tipo de RSD de la élite estudiada se puede concluir que efectivamente se observaron en los nueve indicadores - en unos más que en otros - que están las hegemónicas, las tuvieron un alto grado de consenso en casi todos los miembros de la élite en cuanto a las instituciones, organizaciones o partidos; las emancipadas, aquellas se compartieron, por ejemplo, entre los mismos miembros de una filiación partidista o pertenecientes a la iniciativa privada; y las polémicas o controversiales se observaron en uno de los integrantes.

Con respecto a los modelos de interpretación de las RSD se observaron escasamente tanto en el genético y el estructural como en el dinámico.

Finalmente, con respecto a los indicadores fue todo un acierto su introducción porque generó descripciones y quizás explicaciones sobre las RSD lo que permitió observar la relación existente, en este caso, entre la construcción de lo concreto-abstracto, de la realidad y la teoría, 
de tal manera que significó ver su cualidad, como estrategia de investigación y explicación del fenómeno estudiado.

Con respecto a los indicadores, habría que apunta lo siguiente:

1) En sus relatos los informantes no nos dicen si su designación como candidatos a los puestos de elección popular fue producto de un proceso democrático y menos de aquellos que tuvieron seguro su puesto a diputados plurinominales; o que cómo llegaron a un puesto como la Presidencia del Tribunal Superior de Justicia del Estado sin haber hecho la carrera correspondiente. Uno omite también el hecho de que violó la ley reglamentaria correspondiente a la obtención del título de licenciatura, primero, al haber pasado más de 25 años de concluido sus estudios de licenciatura, segundo, no fue la misma universidad donde la estudió y tercero presentó una tesis que no tenía nada que ver con la naturaleza de su título.

Tampoco hacen referencia, por ejemplo, a que el proceso político en el que se encuentran está cargado de un elitismo tal que restringe sus oportunidades y acceso a las posiciones de poder, amén de privilegiar el rol de las estructuras institucionalizadas para su selección, así como conduce a la expansión de la invocación de legitimidad técnica para el liderazgo, conocida como tecnopolítica que se traduce en un aumento proporcional de personas con mayor dotación de capital educacional en las posiciones de poder político, debilitando así la capacidad representativa de la política, reduciendo el círculo a los que pudieran acceder al poder institucionalizado y que han disfrutado previamente de las oportunidades para acumular educación y capital cultural en general (Delamaza, 2013).

2) Alguien expresa sin empacho que el PVEM le ofreció la candidatura a diputado plurinominal; es decir, que no fue electo. Otro mostró un cariz peculiar, quizás con sentido plural: primero funcionario en la primera administración municipal del PAN, después como presidente del consejo Coordinador Empresarial promovió la precandidatura a Presidente de la República por el PRD de Marcelo Eberard y hoy es candidato a regidor por el mismo PAN.

La TRS señala que la comunicación social es un elemento esencial en la constitución de las RS en este caso de la democracia. Sin embargo, quizás debido a una omisión de mi parte, ninguno relatan cómo se dieron los encuentros, acuerdos, disputas, conflictos, negociaciones y otros elementos de dicha comunicación, entre ellos y cuál pudo haber sido su impacto, quién si tuvo - fue su "padrino", si tuvo que aportar algún monto económico o hubo algún promotor, cómo hizo equipo con alguien para obtener el puesto "anhelado", etc.

3) Así como hay quienes se tuvieron que enfrentar al Presidente de la República en turno, mientras que otros lo han hecho al amparo del poder en turno; alguno tuvo que realizar una campaña para alcanzar algún beneficio partidista. Otro desde su curul propuso iniciativas legislativas y participó en el diseño de alguna ley aprobada. Otro también recibió como "premio" de parte de último gobernador del Partido Revolucionario Institucional, del estado, una "beca completa" para estudiar un año en el extranjero. Así, muchos han recibido alguna tipo de apoyo o promoción política.

Ninguno hace referencia a algún error cometido en alguna decisión tomada por la responsabilidad asumida. Sólo de sus proezas hacen referencia. No hay sentido autocrítico, en pocas palabras. 
4) Con excepción de uno, nadie relata en qué berenjenal pudieron haberse metido al tomar alguna decisión que implicaba algún conflicto de intereses. Si fueron capacitados para ello o fue producto de su intuición u "olfato político".

La mayoría al pensar en la democracia, automáticamente piensa en elecciones; el "votar" es una figura común de la democracia, así como las prácticas no-democráticas demagogia, fraude, autoritarismo, acciones que atentan contra ella y también en contra de esa forma de participación; las votaciones como el centro de una caracterización funcional, expresiones de una realidad política que es parte de nuestra historia y continúa siendo una referencia actual.

No perciben en la democracia valores como la pluralidad y la tolerancia, donde la primera pueda observarse al decir "considérame y considera los otros", "tómenme en cuenta y tomemos en cuenta a los otros" que no sólo es válido en el limitado espacio de la política, sino también es una forma de pensar la vida humana; la tolerancia incluya voces o representaciones hasta antagónicas. Asimismo tampoco hay voces que se refieran a valores como la denuncia de la corrupción e impunidad que impera en el país.

Todos/a reportan que están de acuerdo con el régimen democrático, como una creencia válida. Ese uno en un principio se rehusó a ser entrevistado ya que impugna el derecho de igualdad en los votos: "no puede valer igual el voto de los iletrados que el de los ilustrados". Sin embargo, es necesario acotar que uno de los informantes cuando le informé el objetivo de la entrevista - conocer su visión de la democracia - inmediatamente me dijo que no me la daba debido a que no "creía" en ella. A lo que le refuté que eso quería conocer de él, por lo que finalmente accedió.

Todos/a creen en el régimen democrático con sus peculiaridades. Por lo general, expresan acuerdo, la consideran una creencia y hasta muestran cierto entusiasmo al hablar de ella. La asocian a la prosperidad, a una mejor convivencia, entre otros. Son elementos cohesionantes de la materialidad achacada, quizá los factores aglutinantes del sentido de la realidad asignada. Es como si fuera un ritual, las conversaciones se impregnan de escepticismo, se evocan las prácticas y se intenta ajustar las palabras a las cosas, "la democracia es una creencia", "es un discurso válido de los políticos", para terminar aduciendo su corolario: "hay que votar".

A excepción de dos sujetos, no tienen o hacen referencia como derroteros de la democracia mexicana hechos históricos de gran impacto como fueron el movimiento estudiantil de 1968 y el doloroso aprendizaje cívico en los terremotos de 1985; la insurgencia electoral de 1988 y la función que tuvo; al plebiscito en el Distrito Federal en marzo de 1993 para preguntarle a los ciudadanos su conformidad con el tipo de gobierno de la ciudad; a la marcha a favor del alto a la guerra y por la paz en Chiapas en 1994; a los movimientos sociales de las feministas y los movimientos de lesbianas, gais, bisexuales, y transgéneros; a las grandes movilizaciones de la Coordinadora Nacional de Trabajadores de la Educación en la década de 1980; la impresionante y hasta ahora inigualable convocatoria ciudadana para repudiar el desafuero contra el entonces Jefe de Gobierno del Distrito Federal, Andrés Manuel López Obrador, en abril de 2005; y las innumerables movilizaciones ciudadanas convocaron a millones de citadinos en las calles de la ciudad capital; al \#yosoy132. 
Para la mayoría de los sujetos las RSD son el resultado de la aplicación de sus sentidos, es decir, se reduce a "un mero dato perceptivo"; se trata de un sesgo típico ocasionado por el hecho de que una representación emerge ante los individuos como un dato concreto, por ejemplo en forma de metáfora. Los informantes tienen sus particularidades al desarrollar formas peculiares para la aprehensión de un objeto y cada cual está adscrito a ciertas condiciones y situaciones sociales particulares. Hacer de la democracia un objeto social no extraño, implicaba exponerla a un escrutinio con las categorías prevalecientes sobre "el cómo hacer" la política. Las representaciones tienen la huella de "esa mezcla"; de ahí que pensar el voto como "un resguardo de la democracia" y como una manera - casi sagrada - de garantizar la participación de las mayorías, sean pensamientos elevados a la categoría de elementos irremplazables de la democracia. González Casanova (1965) La democracia en México se planteaba las consecuencias sociales de un sistema de educación pública contagiado de las ideas y los símbolos emanados de regímenes políticamente autoritarios. Todos echan mano de nuestra cultura política para acceder a las ideas acerca de la democracia; para atraer dicho objeto a su territorio de saberes y referencias. Es el proceso de transformación de un objeto extraño en uno accesible. La representación de la democracia, centrada en la pluralidad, puede coexistir con la confianza en el poder de la muchedumbre; es decir, con una fuerza caracterizada en la noción de "todos, unidos".

Son la ciudadanía, en general, los que deberían ser los protagonistas de la construcción de la democracia proyectada en un gobierno ad hoc; toca a la clase política local garantizar que este derecho se plasme en la ley y en los hechos, buscando una sociedad con todo el poder al ciudadano.

5) Aunque la entrevista no pretende evaluar los conocimientos históricos de los informantes, hay en general muy poca información al respecto. Por otro lado, hay una aparente paradoja al mencionar algunos a personajes antagónicos a su ideología o a su partido de origen, así como nadie hace referencia a los caudillos de la revolución como Francisco Villa o Emiliano Zapata, o críticas a presidentes de la República contemporáneos. Son más influyentes personaje familiares o de otras nacionalidades y de campos como la academia, la mercadotecnia, por ejemplo.

6) No perciben que un problema álgido de la democracia es que debe imponerse al mercado para evitar la erosión de la libertad compartida equitativamente por todos. Para identificar los límites del mercado y al mismo tiempo admitir su funcionamiento en el marco de una democracia se necesita el reconocimiento del valor que reconozca el papel de los bienes primarios provistos universalmente por el Estado para asegurar la dimensión positiva de la libertad y encargue al mercado la asignación de los bienes superfluos, con sus virtudes de economía de información y dinamismo. Lo que se ha llamado democracia de mercado se manifiesta en el hecho de que las empresas que buscan el lucro están sujetas, incondicionalmente, a la soberanía del público comprador. El verdadero significado de su crítica, entonces discrepa con la valoración de la producción por parte de los consumidores. Se quita entonces la máscara y muestra sus aspiraciones dictatoriales. La producción no se debería regir por los deseos de la sociedad sino por su propia discreción. Los empresarios y propietarios de los medios de producción no son más que representantes de los consumidores cuyo mandato es renovado o revocado diariamente; señalan la libertad de los individuos para vender su fuerza de 
trabajo y comprar bienes y servicios, que no entra en contradicción con la democracia; la democracia es la libre expresión de las preferencias de bienes y servicios, lo que permite que las diferencias naturales de capacidades $\mathrm{y}$ de patrimonio acumulado produzcan desigualdades sociales.

Hay quien señala una de las formas de la democracia: la deliberativa. Formula cierto escepticismo y realismo. Con respecto a lo primero apunta ciertos alcances y logros efectivos de la democracia deliberativa, ya que manifiesta diversas dudas respecto a la posibilidad de conciliar distintas promesas valorativas de la deliberación democrática. Realismo, porque considera un conjunto de dificultades para dar forma a instituciones y metodologías deliberativas en el contexto de la vida política moderna.

No perciben que la democracia debe imponerse al mercado para evitar la erosión de la libertad compartida equitativamente por todos; para identificar los límites del mercado y al mismo tiempo admitir su funcionamiento en el marco de una democracia. Quizás porque la democracia afecte el lucro de sus empresas. No se perciben como los representantes de los consumidores cuyo mandato es renovado o revocado diariamente.

Por otro lado hay quienes perciben que la democracia en México ha sido consecuencia de un sistema de educación pública impregnado de ideas y símbolos emanados del régimen autoritario que privó por más de 70 años.

Nadie percibe cómo la democracia resulta un proceso complicado de transformación de un objeto extraño en uno accesible. Tampoco se escuchan planteamientos de que es la ciudadanía, en general, la que debería ser el protagonista principal de la construcción de la democracia proyectada en un gobierno ad hoc.

Algunos reconocen las tendencias a "materializar" la democracia: hacia el bienestar común, los derechos humanos, la impartición de justicia, la libre expresión, en contra de las imposiciones y los fraudes, en contra de la inflación.

Asimismo hay quienes esperan mucho de la democracia, como si fuese la llave de las soluciones; no dejan de referir las prácticas que provienen del mundo de la política y que están ahí en la manera de remodelar la democracia. También expresan una idea del bien común tal cual si se tratase de un monolito.

El entrecruzamiento de caminos recorridos en su descripción nos muestra también la perspicacia del pensamiento de sentido común para naturalizar la realidad que se le atribuye.

7) Parecería que el Príncipe Maquiavelo se pudiera imponer en muchos al tener un sentido pragmatista de la política y no tener un código de ética.

Muy pocos se refieren a los principios esenciales de la democracia como son: los derechos humanos, anteriormente identificadas como las garantías individuales; la sustentabilidad y el respeto del medio ambiente como parte del desarrollo; la equidad de género y garantizar el derecho a la ciudad para todos sus habitantes, el derecho a ser ciudadanos plenos. Así como sólo algunos hacen referencia a otros tipos de democracia, aparte de la electoral, como la representativa; pero nadie de la participativa, pivote de todas las acciones históricas de los ciudadanos y el movimiento urbano popular. 
Para la mayoría de nuestros sujetos las representaciones son el resultado de la aplicación de sus sentidos, es decir, se reduce a "un mero dato perceptivo"; se trata de un sesgo típico ocasionado por el hecho de que una representación emerge ante los individuos como un dato concreto, por ejemplo en forma de metáfora. Los informantes tienen sus particularidades al desarrollar formas peculiares para la aprehensión de un objeto y cada cual está adscrito a ciertas condiciones y situaciones sociales particulares. Hacer de la democracia un objeto social no extraño, implicaba exponerla a un escrutinio con las categorías prevalecientes sobre "el cómo hacer" la política. Las representaciones tienen la huella de "esa mezcla"; de ahí que pensar el voto como "un resguardo de la democracia" y como una manera - casi sagrada- de garantizar la participación de las mayorías, sean pensamientos elevados a la categoría de elementos irremplazables de la democracia. González Casanova (1965) La democracia en México se planteaba las consecuencias sociales de un sistema de educación pública contagiado de las ideas y los símbolos emanados de regímenes políticamente autoritarios. Todos echan mano de nuestra cultura política para acceder a las ideas acerca de la democracia; para atraer dicho objeto a su territorio de saberes y referencias. Es el proceso de transformación de un objeto extraño en uno accesible. La representación de la democracia, centrada en la pluralidad, puede coexistir con la confianza en el poder de la muchedumbre; es decir, con una fuerza caracterizada en la noción de "todos, unidos".

Son la ciudadanía, en general, los que deberían ser los protagonistas de la construcción de la democracia proyectada en un gobierno ad hoc; toca a la clase política local garantizar que este derecho se plasme en la ley y en los hechos, buscando una sociedad con todo el poder al ciudadano.

8) Casi nadie hace referencia a la justicia social y por lo mismo no perciben el hecho de que nunca los ricos son más escasos mientras que la pobreza aumenta considerablemente.

Nunca antes se dio el fenómeno de que los 14 latinoamericanos más ricos acumulan fortunas que sumadas superan los 150,000 millones de dólares, cifra que representa el ingreso anual de más de 100 millones de los habitantes más pobres de la región, como también los indígenas ganan entre 35-65\% menos que los hombres blancos.

Prácticamente todos se refieren a una forma de democracia: la electoral, mientras que casi nadie hace referencia a las otras formas. $Y$ casi nadie impugna la partidocracia imperante en la que los partidos políticos controlan las políticas públicas, incluidos los procesos electorales a través de los "consejeros ciudadanos" el INE. Para todos el acto de "votar" es una figura se ha vuelto un fetiche del sistema y para pocos las prácticas no-democráticas como la demagogia, el fraude, el autoritarismo, son acciones que atentan contra la democracia y contra de esa forma de participación.

9) Como se puede observar - en general - es un indicador muy pobre en cuanto a que se expresan pocas experiencias al respecto.

Ninguno de los entrevistados perciben la carencia de políticas públicas enfocadas a fomentar los espacios de debate y encuentro a todo nivel, estimular las iniciativas sociales e individuales, catalizar propuestas y consensos, delegar decisiones y fijar normativas regulatorias, entre otros. 
Asimismo no contemplan la concentración mediática y la lógica que privilegia los intereses de los grandes grupos económicos, para dar paso a una reestructuración que ponga término a los monopolios y oligopolios, que establezca el rescate del carácter público de la comunicación social, que garanticen la participación activa, crítica y organizada de la sociedad en todos los procesos comunicativos, defendiendo el derecho a la libertad de expresión y de recibir información verificada y plural o el derecho a la réplica, entre otros.

Como tampoco observan que uno de los puntos críticos con los medios de comunicación social tiene que ver con el reparto del espectro radioeléctrico que pertenece a la nación y es administrado por el Estado.

\section{Discusión}

Del grupo que no aceptó ser entrevistado puso en evidencia, en el mejor de los casos, su falta de voluntad para expresar su pensamiento democrático, sino es existe una ausencia al no exponerse ante un "extraño".

Sobre la estrategia metodológica, la etnometodología respondió a la naturaleza del paradigma cualitativo, así como la técnica. Sin embargo, ante la falta de experiencia como entrevistador, se pudo observar que hubo cierta falta de pericia para obtener una mayor $y$ mejor información en algunos de los que conformaron la muestra de los informantes, misma que sí respondió, ya que mostró una pluralidad en la unidad de lo que es la élite política. No obstante, casi todos manifiestan que sus RSD se reducen a una democracia electoral.

Se pudo observar que las RSD de la élite leonesa son formas de conocimiento elaboradas y compartidas por ellos que a su vez participan en prácticas sociales comunes y que tiene una determinada inserción en la estructura social, formas que orientara su actuación, estableciendo y orientando comportamientos que soportan su identidad. Así, su contenido depende de los grupos y las relaciones sociales en que han participado, no coexistiendo una RSD homogénea para todos/a los miembros de la élite política.

Al estar tan embebidos en sus actividades políticas, quizás carecen de la información sobre la existencia de las demandas que hay sobre la producción y distribución local y regional; la sustentabilidad de los medios públicos y comunitarios; el acceso a la información de las entidades públicas (transparencia) y acceso universal a las tecnologías de Información y Comunicación (TICs), ente otras.

La memoria puede ser muy frágil y selectiva lo cual puede significar la orientación ideológica o simplemente no considerarlos significativos.

Respecto a la clasificación de las respuestas de acuerdo a los 9 indicadores hay que notar que muchas de las respuestas podrían estar codificadas en más de algún indicador o se pudieran confundir con otro indicador. Sin embargo, las diferencias existen.

Con respecto a la democracia que vive estos momentos México que está muy lejos de las demandas sentidas por amplios sectores de la población. Sí hay, por otro lado, sectores que sólo participan cuando las autoridades aplican alguna política social. Existe un gran descontento y desencanto que ha conducido a intensas movilizaciones y organizaciones de grupos que no son 
escuchados por la clase política que a su vez parece que sólo pone atención en los mecanismos electorales para reproducirse a sí misma dejando profundos déficits en todos los rubros de la vida pública nacional, estatal y locales.

\section{Referencias bibliográficas}

Abric, J. (2004). Prácticas sociales, representaciones sociales. In J-C Abric (comp.). Prácticas Sociales y representaciones. México D.F.: Ediciones Coyoacán.

Ackerman, J. (2014). El mito de la transición democrática. Consultado el 2 de enero de 2015, de: http://soberaniapopularmx.blogspot.mx/2014/05/el-mito-de-la-transiciondemocratica-18.html

Alonso, J. (2002). Democracia amenazada. Instituto Tecnológico y de Estudios Superiores de Occidente: Tlaquepaque, Jalisco

Araya, S. (2002). Las representaciones sociales: ejes teóricos para su discusión. Cuadernos de ciencias sociales, 127, 1-84.

Delamaza, G. (2013). De la elite civil a la elite política. Reproducción del poder en contextos de democratización. Polis, 36, 1-24.

González, F. (2003). Democracy and citizenship: an analysis involving social representations and social subjectivity. In M. Lavallée, S. Vincent, C. Ouellet \& C. Garnier (Eds.). Les représentations sociales. Constructions nouvelles (pp. 217-229). Montreal: GEIRSO. Recuperado el 30 de octubre de 2008, de: http://geirso.uqam.ca/publications/pdf/Section1/Politique/gonzalez.pdf .

González, F. (2007). Democracy and citizenship: an analysis involving social representations and social subjectivity. Recuperado el 5 de septiembre de 2008, de: http://geirso.uqam.ca/publications/pdf/Section1/Politique/gonzalez.pdf.

González Casanova, P. (1965). La democracia en México. México, D.F.: Ediciones Era.

Ibáñez, T. (1994). Psicología Social Constructivista. Guadalajara: Universidad de Guadalajara.

Íniguez, L., \& Vázquez, F. (1995). Legitimidad del sistema democrático. Análisis de un discurso autorreferencial. In O. D'Adamo, V. García \& M. Montero (Comps.). Psicologia de la Acción Política. Buenos Aires: Paidós.

Íñiguez, L., \& Vázquez, F. (2006). La democracia no es democracia sino sentido común. Notas críticas y alguna constatación práctica. Consultado el 14 de julio de 2009, de: http://antalya.uab.es/liniguez/Materiales/democracia.pdf.

Marková, I. (2003). Dialogicality and Social Representations: The Dynamics of Mind. Cambridge: University Press.

Markova, I. (2004). Trust and Democratic Transition in Post-communist Europe. Oxford: University Press.

Martínez, M. (2006). La investigación cualitativa (Síntesis conceptual). Revista IIPSI, 9(1), 123-146.

Meyer, L (2007). El espejismo democrático. De la euforia del cambio a la Continuidad. México, D.F.: Océano.

Moscovici, S. (1979). El psicoanálisis, su imagen y su público. Buenos Aires: Huemul.

Moscovici, S. (1993). La démocratie et rien d'autre. Faut-il avoir peur de la démocratie? Le genre humaine, 26, 3147.

Moscovici, S. (2007). Espacios imaginarios y representaciones sociales. Aportes desde Latinoamérica. Barcelona: Anthropos y Universidad Autónoma Metropolitana-I.

Navarrete, J. P. (2008). Sistema político mexicano: desarrollo y reacomodo del poder. Iberoforum, III(6), $131-148$. 
Parras, P. (2010). Cultura política de la democracia en México. Consolidación democrática en las Américas en tiempos difíciles. Consultado el 10 de octubre de 2012 de: http://www.vanderbilt.edu/lapop/mexico/2010culturapolitica.pdf.

Pererá, M. (2005). A propósito de las representaciones sociales. Apuntes Teóricos, trayectoria y actualidad. Recuperado el 3 de octubre de 2008, de:

http//:www.bibliotecavirtual.clacso.org.ar/ar/libros/cuba/cips/caudales05/Caudales ARTICULOS/ArticulosPDF/02P075.pdf.

Rodríguez, T. (2003). El debate de las representaciones sociales en la psicología social. Relaciones, 93(XXIV), 53-80.

Rodríguez, T. (2007). Sobre el estudio cualitativo de la estructura de las representaciones sociales. In T. Rodríguez \& M. L. García (Coords.). Representaciones sociales. Teoría e investigación. Guadalajara: Universidad de Guadalajara.

Svampa, M. (2007). Las figuras de la democracia. Recuperado el 10 de abril de 2008, de: http://www.clacso.org.ar/difusion/secciones/osal/enlaces/documentos/las-figuras-de-lademocracia.pdf/view. 